\title{
BMJ Open Medication adherence in multiple sclerosis as a potential model for other chronic diseases: a population-based cohort study
}

\author{
Charity Evans (D) , ${ }^{1}$ Ruth Ann Marrie, ${ }^{2}$ Shenzhen Yao (D) , ${ }^{3}$ Feng Zhu, ${ }^{4}$ \\ Randy Walld, ${ }^{5}$ Helen Tremlett (D) , ${ }^{4}$ David Blackburn, ${ }^{1}$ Elaine Kingwell ${ }^{4}$
}

To cite: Evans C, Marrie RA, Yao S, et al. Medication adherence in multiple sclerosis as a potential model for other chronic diseases: a populationbased cohort study. BMJ Open 2021;11:e043930. doi:10.1136/ bmjopen-2020-043930

\section{- Prepublication history and} additional material for this paper are available online. To view these files, please visit the journal online (http://dx.doi. org/10.1136/bmjopen-2020043930).

Received 17 August 2020 Revised 20 January 2021 Accepted 22 January 2021

Check for updates

(c) Author(s) (or their employer(s)) 2021. Re-use permitted under CC BY-NC. No commercial re-use. See rights and permissions. Published by BMJ.

${ }^{1}$ College of Pharmacy and Nutrition, University of Saskatchewan, Saskatoon, Saskatchewan, Canada

Internal Medicine, University of Manitoba, Winnipeg, Manitoba, Canada

${ }^{3}$ Saskatchewan Health Quality Council, Saskatoon, Saskatchewan, Canada

${ }^{4}$ Neurology, The University of British Columbia Faculty of

Medicine, Vancouver, British

Columbia, Canada

${ }^{5}$ Manitoba Centre for Health Policy, University of Manitoba, Winnipeg, Manitoba, Canada

Correspondence to

Dr Charity Evans;

charity.evans@usask.ca

\section{ABSTRACT}

Objective To determine whether better medication adherence in multiple sclerosis (MS) might be due to specialised disease-modifying drug (DMD) support programmes by: (1) establishing higher adherence in MS than in other chronic diseases and (2) determining if higher adherence is associated with patient-specific or treatment-specific factors.

Design Retrospective cohort study with data from 1 January 1996 to 31 December 2015.

Setting Population-based health administrative data from three Canadian provinces.

Participants Individual cohorts were created using validated case definitions for MS, epilepsy, Parkinson's disease $(P D)$ and rheumatoid arthritis $(R A)$. Subjects were included if they received $\geq 1$ dispensation for a diseaserelated drug between 1 January 1997 and 31 December 2014.

Main outcome measure(s) Proportion of subjects with optimal adherence $(\geq 80 \%)$ measured by the medication possession ratio 1 year after the index date (first dispensation of disease-related drug).

Results 126478 subjects were included in the primary analysis (MS, $n=6271$; epilepsy, $n=55739$; PD, $n=21$ 304; $R A, n=43$ 164). Subjects with epilepsy (adjusted OR, aOR $0.29 ; 95 \% \mathrm{Cl} 0.19$ to 0.45 ), PD (aOR 0.42; $95 \% \mathrm{Cl} 0.29$ to 0.63 ) or RA (aOR $0.26 ; 95 \% \mathrm{Cl} 0.19$ to 0.35 ) were less likely to have optimal 1-year adherence compared with subjects with MS. Within the MS cohort, adherence was higher for DMD than for chronic-use non-MS medications, and no consistent patient-related predictors of adherence were observed across all four non-MS medication classes, including having optimal adherence to DMD.

Conclusions Subjects with MS were significantly more likely to have optimal 1-year adherence than subjects with epilepsy, RA and PD, and optimal adherence appears related to treatment-specific factors rather than patientrelated factors. This supports the hypothesis that higher adherence to the MS DMDs could be due to the specialised support programmes; these programmes may serve as a model for use in other chronic conditions.

\section{INTRODUCTION}

Almost two decades ago, WHO released their Adherence to Long Term Therapies:
Strengths and limitations of this study

- One of the first studies to compare adherence in different chronic diseases using the same populationbased data sources and methodologies.

- Established that adherence is better in multiple sclerosis (MS) than other comparable chronic diseases; higher adherence appears to be related to drugspecific, rather than patient-related factors.

- The strategies used for supporting patients prescribed disease-modifying drugs for MS may serve as a model for improving adherence to other chronic medications.

- Observational studies contain potential unknown confounders.

- Some clinical information is not available in administrative data.

Evidence for Action report estimating that only $50 \%$ of individuals were adherent to their chronic medications. ${ }^{1}$ Since that time, a multitude of research has demonstrated the impact of medication non-adherence on health outcomes and healthcare systems, ${ }^{2-5}$ including increased healthcare utilisation, morbidity and mortality. ${ }^{4-7}$ Annual costs of medication non-adherence are estimated to be between US $\$ 100-$ US $\$ 290$ billion in the USA, $€ 1.25$ billion in Europe and \$C7-\$C9 billion in Canada. ${ }^{38}$

Reasons for non-adherence are complex and few predictors have been consistently associated with levels of adherence across diseases. ${ }^{29}$ Further complicating, this is the lack of consistency and standardisation in how medication adherence is studied. ${ }^{10}$ While numerous studies have examined adherence in many diseases and for various medications, results are often conflicting and comparisons are difficult due to differences in study design, data sources, outcome measures and adherence definitions. It has been suggested 
that improving medication adherence will have more beneficial impact on health outcomes than the development of new therapies. ${ }^{1}$ Despite this, there has been little success to date in identifying effective interventions to improve medication adherence. ${ }^{4511} 12$

In previous work, we have shown that adherence to disease-modifying drugs (DMDs) in multiple sclerosis (MS) is higher than what has been reported for many chronic-use medications in other diseases. ${ }^{13}{ }^{14}$ We hypothesised that this higher adherence in MS is due to the specialised management and support provided to individuals who are prescribed DMDs in Canada. However, to test this hypothesise, we first needed to firmly establish that adherence was actually higher in MS than in other populations, and that the findings were not explained by differences in methodology between studies. To do this, we compared adherence to DMDs in MS with adherence to disease-specific medications in three other chronic conditions using similar population-based cohorts, methodology and outcomes from three Canadian provinces. Second, as adherence can be influenced by many different factors, ${ }^{14}$ we examined adherence to chronic-use nonDMD medications in the MS cohort to determine if the higher adherence was associated with patient-related or treatment-specific factors.

\section{METHODS}

\section{Data source}

This retrospective cohort study used population-based health administrative data from three Canadian provinces, Manitoba (MB), Saskatchewan (SK) and British Columbia (BC) from 1 January 1996 to 31 December 2014 (BC) or 31 December 2015 (MB, SK). Each provincial government maintains linkable health administrative databases that capture information on virtually all $(>99 \%)$ residents. We accessed databases that contained registration (ie, residency) and demographic information, hospital separations, physician services and prescription drug dispensations. International Classification of Diseases (ICD) codes (ICD-9 or ICD-10-CA) are used to record diagnoses in the hospital and physician databases, and the prescription drug databases provide information on all prescribed medications dispensed in an outpatient setting, including the unique drug identification number that is linkable to the Anatomical Therapeutic Chemical (ATC) classification system. ${ }^{15-19}$

MB data were accessed through the MB Population Research Data Repository at the MB Centre for Health Policy, SK data was accessed at the SK Health Quality Council under data sharing agreements with the SK Ministry of Health and eHealth SK, and BC data were accessed through Population Data BC. ${ }^{20}$ As per individual provincial data agreements, no additional data are available.

\section{Study cohorts}

We used validated administrative case definitions involving combinations of hospital, physician and prescription claims, to create individual cohorts for each of the following four diseases: MS, ${ }^{21}$ rheumatoid arthritis (RA), ${ }^{22}$ epilepsy ${ }^{23}$ and Parkinson's disease (PD) ${ }^{24}$ (online supplemental eAppendix). We then identified subjects within each disease cohort who had at least one dispensation for a specific disease-related drug (as listed in online supplemental eAppendix) between 1 January 1997 and 31 December 2014 for use in the primary analyses. If a subject received a disease-related drug from more than one disease group during the study period, the first of the disease-related drugs dispensed was used to assign the disease cohort. We selected these three diseases as they allowed for comparability on non-demographic factors that might affect adherence, such as type of disease course (relapsing remitting with underlying progression (MS and RA) vs gradual progression only (PD)), the length of time until the consequence of non-adherence are realised (immediate (epilepsy, PD) vs delayed (MS)), potential adverse effects, route of drug administration (oral vs injection/infusion) and drug costs. Each of these diseases also has a significant impact on the healthcare system, and patient-related outcomes, including quality of life. ${ }^{25}{ }^{26}$ Disease-specific medications for inclusion in the adherence calculations were selected based on their ATC classifications (eg, antiepileptics) ${ }^{15}$ previous inclusion in adherence studies ${ }^{27-30}$ and availability in Canada during the study period.

The date of the first dispensation after 1 January 1997 for a disease-related drug was defined as the index date. Because many of the study drugs are contraindicated or discouraged in pregnancy, we identified all subjects with a claim for a delivery (ICD-9: V27, ICD-10: Z37) and censored their data 365 days prior to their delivery date. Subjects with less than 1 year of residency in their respective province before or after the index date were excluded. To ensure only incident users were included in the analyses, subjects with a dispensation for any study drug associated with their disease cohort (online supplemental eAppendix) in the 1 year before the index date were excluded.

\section{Patient and public involvement}

Patients and/or the public were not involved in the design or conduct of this study.

\section{Study outcomes}

The primary outcome was the proportion of subjects with optimal adherence measured 1 year after the index date. The first year of therapy was purposefully selected for the primary outcome, as it has been recognised as the most critical time for non-adherence. ${ }^{2}{ }^{31}$ Adherence was estimated using the medication possession ratio (MPR), calculated as the sum of the days' supply for all study drug dispensations during the observation period divided by the number of days in the observation period. In SK, a days' supply variable was not available. As most prescriptions in SK are dispensed in 1-month quantities, we made the assumption that each dispensation of a disease-specific 
drug contained a 30-day supply. An MPR $\geq 80 \%$ was considered optimal. ${ }^{2}$ Secondary outcomes included the proportion of subjects with optimal adherence at years 2, 3, 4 and 5 after the index date, in those subjects with adequate follow-up available. We also examined non-persistence to the disease-related medications, measured as the proportion of subjects who discontinued the medication after only one dispensation, within the first 6 months, and within the first year of therapy; these three outcomes were mutually exclusive. A discontinuation was defined as a continuous gap with no disease-related medication $>90$ days. As a sensitivity analyses, we estimated adherence over the same time periods using the proportion of days covered (PDC), which can provide a more conservative estimate of adherence, especially when switches within a medication class can occur. ${ }^{32}$ The PDC was calculated as the number of days covered by drug dispensations during the observation period divided by the number of days in the observation period. ${ }^{33}$ All study outcomes were estimated by class effect (eg, all antiepileptic drugs) and switching between medications was allowed.

Within the MS disease cohort only, we identified those subjects who had at least one dispensation for one of the following medication classes, categorised using the $\mathrm{ATC}^{15}$ classifications: HMG-CoA reductase inhibitors (statins; ATC: C01AA), ACE inhibitors (ACEI; ATC: C09AA), angiotensin receptor blockers (ARB; ATC: C09CA), and thyroid hormone replacement therapies (ATC: H03AA). These medication classes were selected based on their frequency of use in MS. ${ }^{34}{ }^{35}$ We estimated adherence and persistence for incident users of each of these four medication classes using the same methods as described above, except we used the quantity dispensed to determine the days' supply in SK, as these medications are primarily prescribed as once daily dosing.

\section{Statistical analysis}

We described baseline characteristics of the subjects using frequencies, means and SD. To identify potential predictors of optimal adherence among the disease cohorts at 1 year, we used multivariable logistic regression with the following covariates measured at the index date (date of first drug dispensation): age (continuous), sex, location (urban vs rural), median household income estimated by linking the first three digits of postal ('zip') code to Canadian census data (reported as quintiles), and calendar year (1997-1998, 1999-2000, 2001-2002, 2003-2005, 20062008, 2009-study end). We also adjusted for the number of physician visits $(0-3,4-11, \geq 12)$, hospitalisations $(0, \geq 1)$ and non-study prescription medication classes dispensed $(0,1-2,3-4, \geq 5)$ in the year before the index date as a measure of prior healthcare utilisation. Logistic regression models, with the same covariates described above were used to identify predictors of 1 year persistence for the disease cohorts. Models were checked for multicollinearity (variance inflation factor $>2.5$ ) and goodness of fit (Hosmer-Lemshow, $\mathrm{p}>0.05) .{ }^{36}$ Results were reported as adjusted OR (aOR) with $95 \%$ CIs.

In the MS cohort, potential predictors of 1-year adherence for each of the chronic-use medication classes were assessed for subjects who received at least one dispensation for a DMD, using logistic regression models with the following covariates measured at the index date: age (continuous), sex, location (urban vs rural), median household income estimated by linking the first three digits of postal code to Canadian census data (reported as quintiles) and calendar year (continuous). Calendar year was included as a continuous variable in these models because the smaller cohort size. We also adjusted for the mean number of physician visits, hospitalisations and prescription medication classes dispensed in the year before the index date as a measure of prior healthcare utilisation, and whether or not the subject had optimal 1-year adherence (MPR $\geq 80 \%$ ) to their DMDs.

As per provincial data regulations, analyses were performed separately in each province and combined using random effects meta-analysis. Random effects models were chosen because tests for heterogeneity $\left(\mathrm{I}^{2}\right.$ indicated moderate $(25 \%-50 \%)$ to high $(>75 \%)$ levels of heterogeneity between outcomes from the three provinces. ${ }^{13} 37$ Statistical analyses were generated using SAS software, V.9.4 of the SAS System for Windows (SAS Institute), and R software V.3.6.1 (R Foundation for Statistical Computing, Vienna, Austria, 2019).

\section{RESULTS}

A total of 126478 subjects were included in the primary analysis (MS, $\mathrm{n}=6271$; epilepsy, $\mathrm{n}=55$ 739; PD, $\mathrm{n}=21$ 304; RA, n=43 164) (figure 1A). There were no notable differences in the characteristics of each disease cohort between provinces (table 1). Within the overall MS cohort (ie, with or without a DMD dispensation during the study period, $\mathrm{n}=28$ 176), 13780 subjects were identified as receiving at least one dispensation for a statin $(n=4628)$, ACEI $(n=4569)$, ARB $(n=1971)$ or thyroid replacement $(\mathrm{n}=2612)$ medication, and were included in the analyses (figure 1B, online supplemental eTable 1).

The proportion of subjects with optimal adherence (MPR) at 1 year was highest for the MS cohort $(77.2 \%$, 95\% CI $72.4 \%$ to $81.3 \%)$, followed by PD $(61.0 \%, 95 \%$ CI $54.9 \%$ to $66.8 \%$ ), epilepsy $(50.9 \%$, $95 \%$ CI $42.5 \%$ to $59.3 \%)$ and RA $(47.0 \%, 95 \%$ CI $45.4 \%$ to $48.8 \%)$ (table 2). The proportion of subjects with optimal adherence consistently decreased over the 5-year period for all diseases. Similar results were observed for the sensitivity analyses where the PDC adherence measure was used (table 2). Non-persistence was lowest in the MS cohort, with approximately $17 \%$ of subjects discontinuing all DMD within the first year of therapy. Levels of non-persistence varied between diseases, although most non-persistent subjects in each cohort discontinued their 


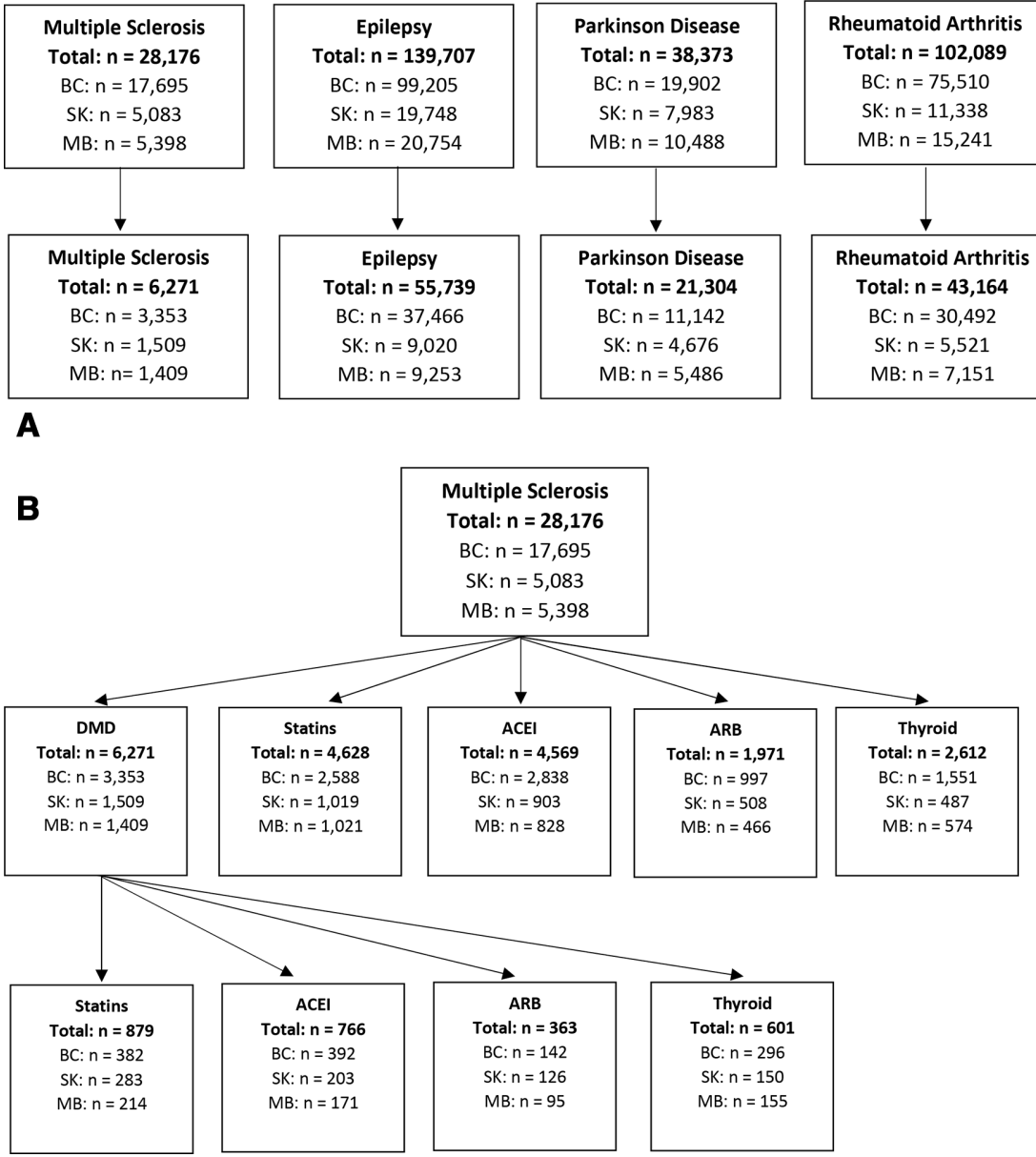

Subjects identified in administrative data during study period

Subjects included in analyses:

-At least one dispensation for study drug during study period

At least one year residency in

responsive province before and after index date

-No dispensation for study drug in one year before index date

Subjects identified in administrative data during study period

Subjects included in adherence analyses (Table 4): -At least one dispensation for study drug during study period -At least one year residency in responsive province before and after index date

-No dispensation for study drug in one year before index date

\section{Subjects with at least one dispensation for a DMD and a chronic-use medication during study period (Table 5):}

Figure 1 Flow diagram of subjects for study cohorts. ACEI, ACE inhibitor; ARB, angiotensin receptor blocker; BC, British Columbia; DMD, disease-modifying drug; MB, Manitoba; SK, Saskatchewan.

disease-related medications within the first 6 months of starting therapy (table 2).

After adjustment for potential confounders, subjects with MS were statistically significantly more likely to have optimal adherence than subjects with PD (aOR 0.42; 95\% CI 0.29 to 0.63 ), epilepsy (aOR $0.29 ; 95 \%$ CI 0.19 to 0.45 ) or RA (aOR $0.26 ; 95 \%$ CI 0.19 to 0.35 ) at 1 year. Optimal adherence decreased as the time since initiation (index date) increased, and was associated with increased healthcare (physician and hospital) contact in the year before the index date and a higher median household income level (table 3). A higher number of prescription medications in the year before the index date was associated with lower adherence levels; age and sex were not associated with adherence. Similar associations were observed for persistence at 1 year (table 3).

Within the MS cohort, 1-year adherence was highest for the DMDs $(77.2 \%$; $95 \%$ CI $72.4 \%$ to $81.3 \%$ ), followed by thyroid replacement $(72.3 \%$; $95 \%$ CI $68.1 \%$ to $76 \% .1)$, ARB $(60.3 \% ; 95 \%$ CI $56.7 \%$ to $63.8 \%)$, statins $(55.3 \%$; $95 \%$ CI $51.0 \%$ to $59.4 \%)$ and ACEI $(54.7 \%$; $95 \%$ CI $53.3 \%$ to $56.2 \%$ ). As indicated by non-overlapping confidence intervals, the difference in adherence was statistically significant for ARB, statins and ACEI. Persistence levels varied among the medication classes, but the majority of subjects who discontinued within the first year of therapy did so in the first 6 months (table 4 ).

Within the MS cohort, no consistent predictors of adherence were observed across all four non-MS medication classes (table 5). Optimal 1-year adherence to DMDs was associated with increased odds of optimal 1-year adherence to a non-MS medication class, but only reached statistical significance for ACEI (aOR 1.83; 95\% CI 1.23 to 2.71$)$.

\section{DISCUSSION}

For this retrospective cohort study, we used populationbased health administrative data, and found that 1-year adherence to disease-specific therapy was highest in MS when compared with epilepsy, PD and RA. Early discontinuations appeared to be a major reason for nonadherence, as up to $30 \%$ of subjects discontinued all antiepileptics or RA medications within the first 6 months of therapy. This impact of early discontinuations is consistent with evidence from other disease cohorts. ${ }^{38-40}$ Adherence levels decreased with increased time since initiation in all disease cohorts. We also found that, within the MS cohort, adherence was higher to the DMDs than to other chronic-use non-MS medications. 


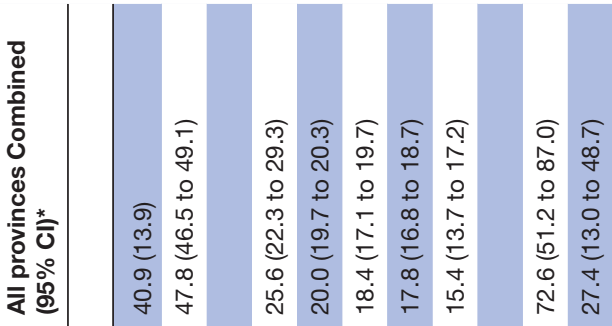

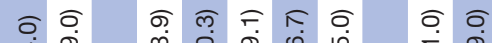

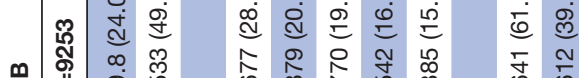

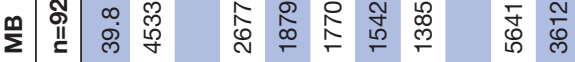

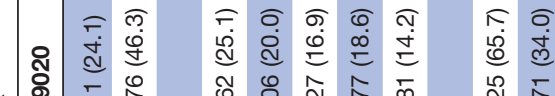

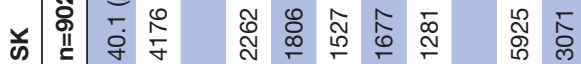

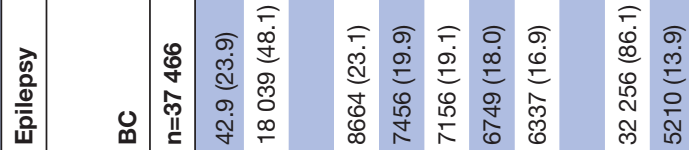

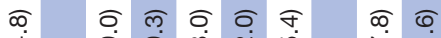

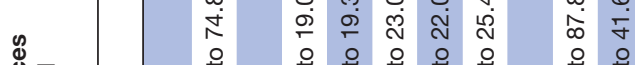

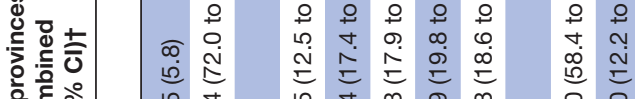

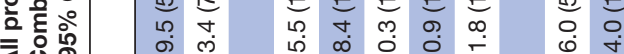

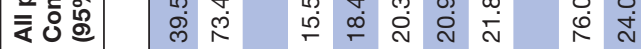

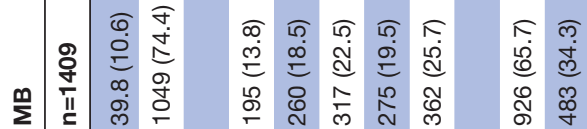
ช ใ

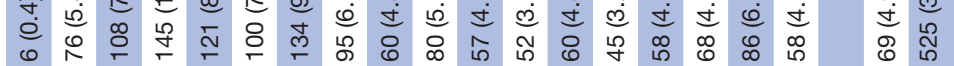

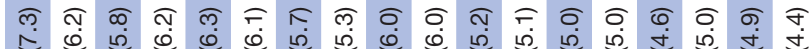

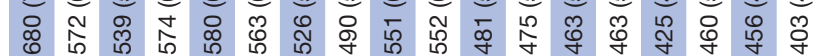

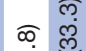
ఫ

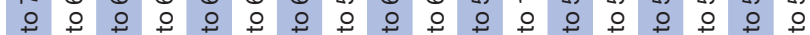

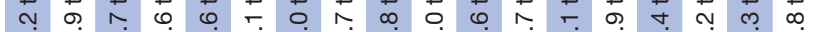

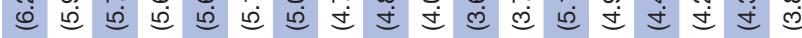
仓ं

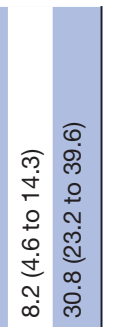

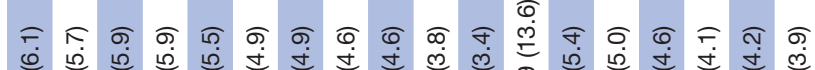

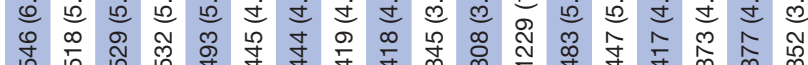

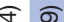
ำ $\stackrel{ָ}{\check{N}}$

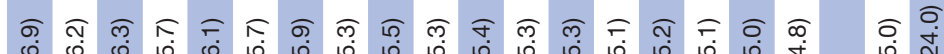

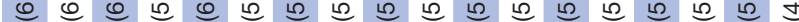
息 点

एִ

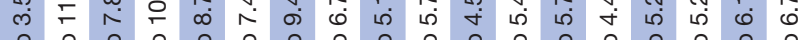
웅ㅇㅇㅇㅇㅇㅇㅇㅇㅇㅇㅇㅇㅇㅇㅇㅇㅇㅇㅇㅇㅇㅇㅇㅇㅇ

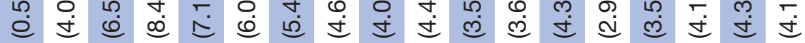

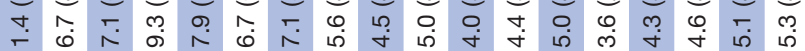

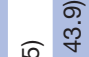
당ㅇ 웅 $\stackrel{\infty}{\stackrel{\infty}{*}}$ ํㅓㅁ

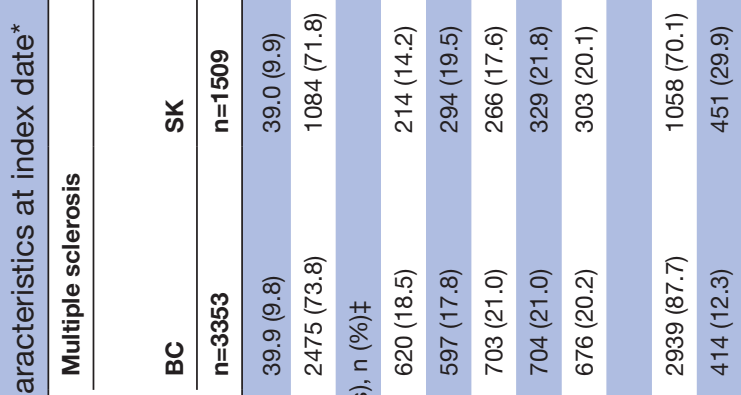

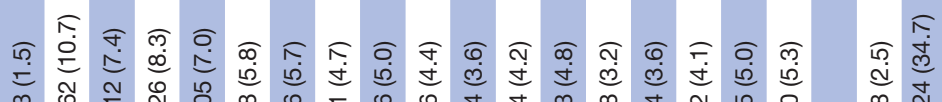

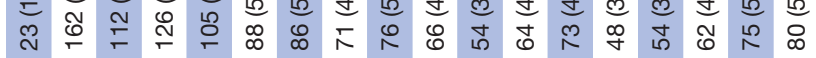

觉

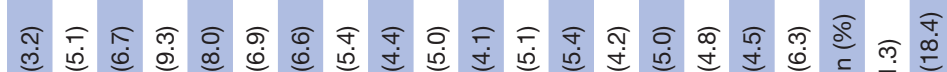

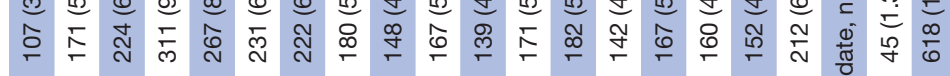

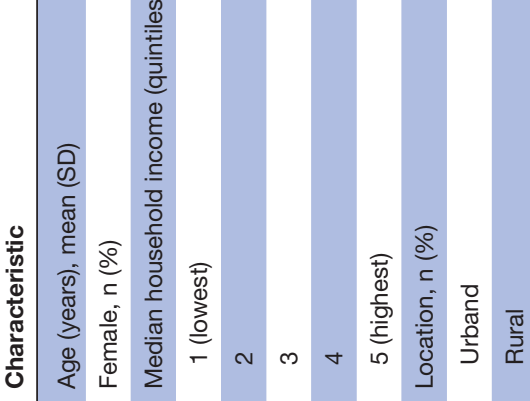

$\sqrt{\frac{0}{c}}$ 


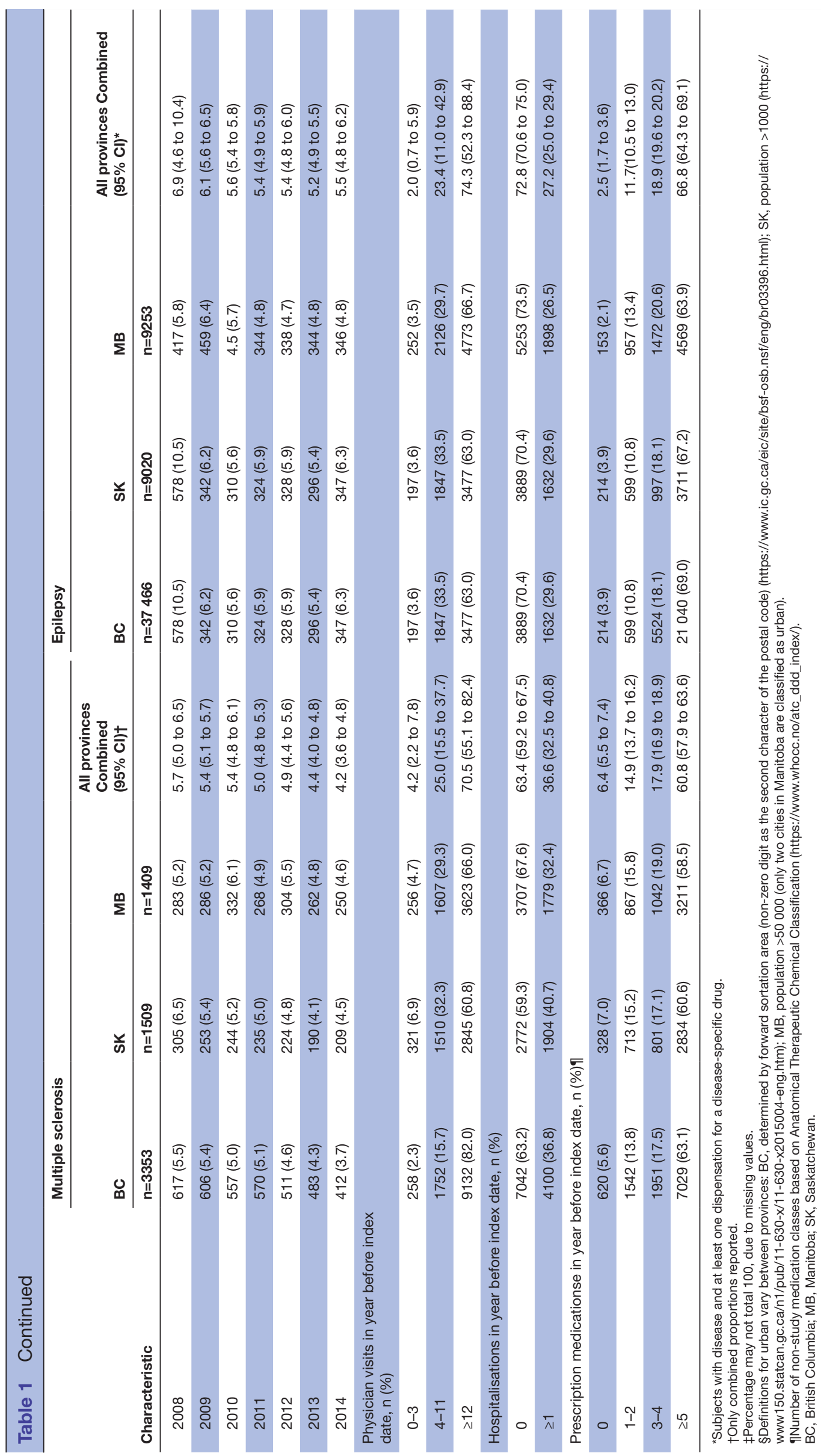


Table 2 Disease-specific adherence and persistence (all provinces combined)

\begin{tabular}{|c|c|c|c|c|}
\hline & Multiple sclerosis & Epilepsy & Parkinson disease & Rheumatoid arthritis \\
\hline Measure & $\mathrm{n}=6271$ & $\mathrm{n}=55739$ & $n=21304$ & $n=43164$ \\
\hline \multicolumn{5}{|c|}{ Medication possession ratio $\geq 80 \%, n(\%, 95 \% \mathrm{Cl})$} \\
\hline Year 1 & $4757 / 6271(77.2,72.4$ to 81.3$)$ & $28247 / 55739(50.9,42.5$ to 59.3$)$ & $13173 / 21304(61.0,54.9$ to 66.8$)$ & $\begin{array}{l}20605 / 43164(47.0,45.4 \text { to } \\
48.8)\end{array}$ \\
\hline Year 2 & $3854 / 5769(68.3,62.7$ to 73.3$)$ & $23330 / 50615(45.7,37.5$ to 54.2$)$ & $11837 / 19388(59.6,53.5$ to 65.4$)$ & $\begin{array}{l}16183 / 39809(40.1,38.9 \text { to } \\
41.4)\end{array}$ \\
\hline Year 3 & $3238 / 5332(62.1,56.7$ to 67.2$)$ & $19875 / 46047(42.4,34.9$ to 50.3$)$ & $10539 / 17351(59.0,51.4$ to 66.1$)$ & $\begin{array}{l}13574 / 36656(36.4,34.7 \text { to } \\
38.0)\end{array}$ \\
\hline Year 4 & $2815 / 4953(58.1,53.0$ to 63.1$)$ & $17301 / 41863(40.5,33.6$ to 47.8$)$ & $9273 / 15309(58.9,48.8$ to 68.3$)$ & $\begin{array}{l}11726 / 33608(34.4,32.8 \text { to } \\
36.1)\end{array}$ \\
\hline Year 5 & $2461 / 4606(54.5,50.1$ to 58.8$)$ & $15096 / 37977(38.7,32.1$ to 45.8$)$ & $8044 / 13380(58.7,45.9$ to 70.4$)$ & $\begin{array}{l}10198 / 30695(32.8,30.9 \text { to } \\
34.8)\end{array}$ \\
\hline \multicolumn{5}{|c|}{ Proportion Days Covered $\geq 80 \%, n(\%, 95 \%$ Cl) } \\
\hline Year 1 & $4698 / 6271(75.9,73.0$ to 78.5$)$ & $27339 / 55739(48.7,41.5$ to 56.0$)$ & $12706 / 21304(58.5,52.9$ to 63.9$)$ & $\begin{array}{l}19953 / 43164(44.8,41.8 \text { to } \\
47.8)\end{array}$ \\
\hline Year 2 & $3818 / 5769(67.4,62.6$ to 71.9$)$ & $22442 / 50615(43.6,35.8$ to 51.7$)$ & $\begin{array}{l}11406 / 19388 \\
(57.2,50.9 \text { to } 63.3)\end{array}$ & $\begin{array}{l}15696 / 39809(38.5,36.3 \text { to } \\
40.7)\end{array}$ \\
\hline Year 3 & $3209 / 5332(61.4,56.5$ to 66.1$)$ & $19055 / 46047(40.4,33.1$ to 48.2$)$ & $\begin{array}{l}10117 / 17351 \\
(56.5,48.9 \text { to } 63.8)\end{array}$ & $\begin{array}{l}13119 / 36656(34.7,32.1 \text { to } \\
37.3)\end{array}$ \\
\hline Year 4 & $2788 / 4953(57.4,53.8$ to 60.9$)$ & $16502 / 41863(38.4,31.6$ to 45.7$)$ & $8861 / 15309(56.2,46.6$ to 65.4$)$ & $\begin{array}{l}11311 / 33608(32.8,30.5 \text { to } \\
35.2)\end{array}$ \\
\hline Year 5 & $2452 / 4606(54.2,50.1$ to 58.3$)$ & $14341 / 37977(36.6,30.0$ to 43.7$)$ & $7641 / 13380(55.6,43.7$ to 67.0$)$ & $\begin{array}{l}9806 / 30695(31.2,28.7 \text { to } \\
33.8)\end{array}$ \\
\hline $\begin{array}{l}\text { Discontinued within the } \\
\text { first } 365 \text { days, } n(\% \text {, } \\
95 \% \mathrm{Cl})\end{array}$ & $1113(17.7,16.8$ to 18.7$)$ & $24162(43.3,42.9$ to 43.8$)$ & $6629(31.1,30.5$ to 31.7$)$ & $19132(44.3,43.9$ to 44.8$)$ \\
\hline $\begin{array}{l}\text { Discontinued after only } \\
\text { one dispensation, } \mathrm{n}(\% \text {, } \\
95 \% \mathrm{Cl})\end{array}$ & $168(2.6,2.0$ to 3.3$)$ & 9434 (15.6. 12.5 to 19.2$)$ & $2458(11.9,10.3$ to 13.8$)$ & $4968(13.1,9.5$ to 18.0$)$ \\
\hline $\begin{array}{l}\text { Discontinued within first } \\
180 \text { days, }{ }^{*} \mathrm{n}(\%, 95 \% \mathrm{Cl})\end{array}$ & $411(5.9,4.3$ to 8.2$)$ & $9897(16.0,12.7$ to 19.9$)$ & $2881(13.4,12.6$ to 14.2$)$ & $8746(18.2,14.5$ to 22.4$)$ \\
\hline $\begin{array}{l}\text { Discontinued between } \\
\text { day } 181 \text { and } 365, \mathrm{n}(\% \text {, } \\
95 \% \mathrm{Cl})\end{array}$ & $534(8.2,6.9$ to 9.7$)$ & $4831(8.8,7.7$ to 9.9$)$ & $1290(6.1,5.7$ to 6.4$)$ & $5418(12.1,11.2$ to 13.2$)$ \\
\hline
\end{tabular}

Numerators include number of subjects with sufficient follow-up available for each time period.

*Excluding those who discontinued after only one dispensation.

It is often assumed that individuals with a chronic, potentially disabling disease will be fully motivated to adhere to drug treatment; in reality this can be quite different. Reviews of the literature estimate $33 \%-88 \%$ of individuals with $\mathrm{MS},{ }^{41} 20 \%-75 \%$ with epilepsy, ${ }^{29} 30 \%-80 \%$ with $\mathrm{RA}^{27}$ and $10 \%-67 \%$ with $\mathrm{PD}^{28}$ have good adherence to their disease-specific medications. This wide variability is due to differences in data sources and study methodologies, and makes comparisons within and between diseases difficult. Our study addressed this limitation by using identical data sources, time periods, methodology and outcomes. Our finding that subjects with MS were significantly more likely to have optimal 1-year adherence to their disease-specific medications compared with subjects with epilepsy, RA and PD, establishes that adherence to disease-specific therapies is better in MS than in other chronic diseases.

Although adherence decreased over the first 5 years of therapy in all disease cohorts, the decrease was greatest in the MS cohort. As therapy-related and disease-related factors such treatment regimen and disease duration have not been consistently associated with adherence, ${ }^{42} 43$ we hypothesise this may be due to the lack of consensus on how long individuals living with MS should be treated with DMDs. While other chronic conditions, including those in this study, require indefinite treatment, this is not the case with MS. As MS progresses, inflammation becomes less prominent and the current DMDs become less effective. In many cases, healthcare payers and insurance plans discontinue coverage of the DMDs once a certain level of progression or disability has been reached. ${ }^{13}$ Because of this, it is difficult to assess longterm adherence in MS, which is another reason we chose to focus our primary analyses on the first year of treatment.

When we examined the MS cohort specifically, we found that adherence was higher, in some cases significantly, to DMD compared with other non-MS chronic medications. This suggests that the high level of DMD adherence is likely related to DMD-specific factors, rather than patient-level factors. This is further supported by the observation that no consistent predictors of adherence 
Table 3 Predictors of adherence and persistence at 1 year (all provinces combined)

Adherence $\geq 80 \%$ at Year 1

OR (95\% Cl)

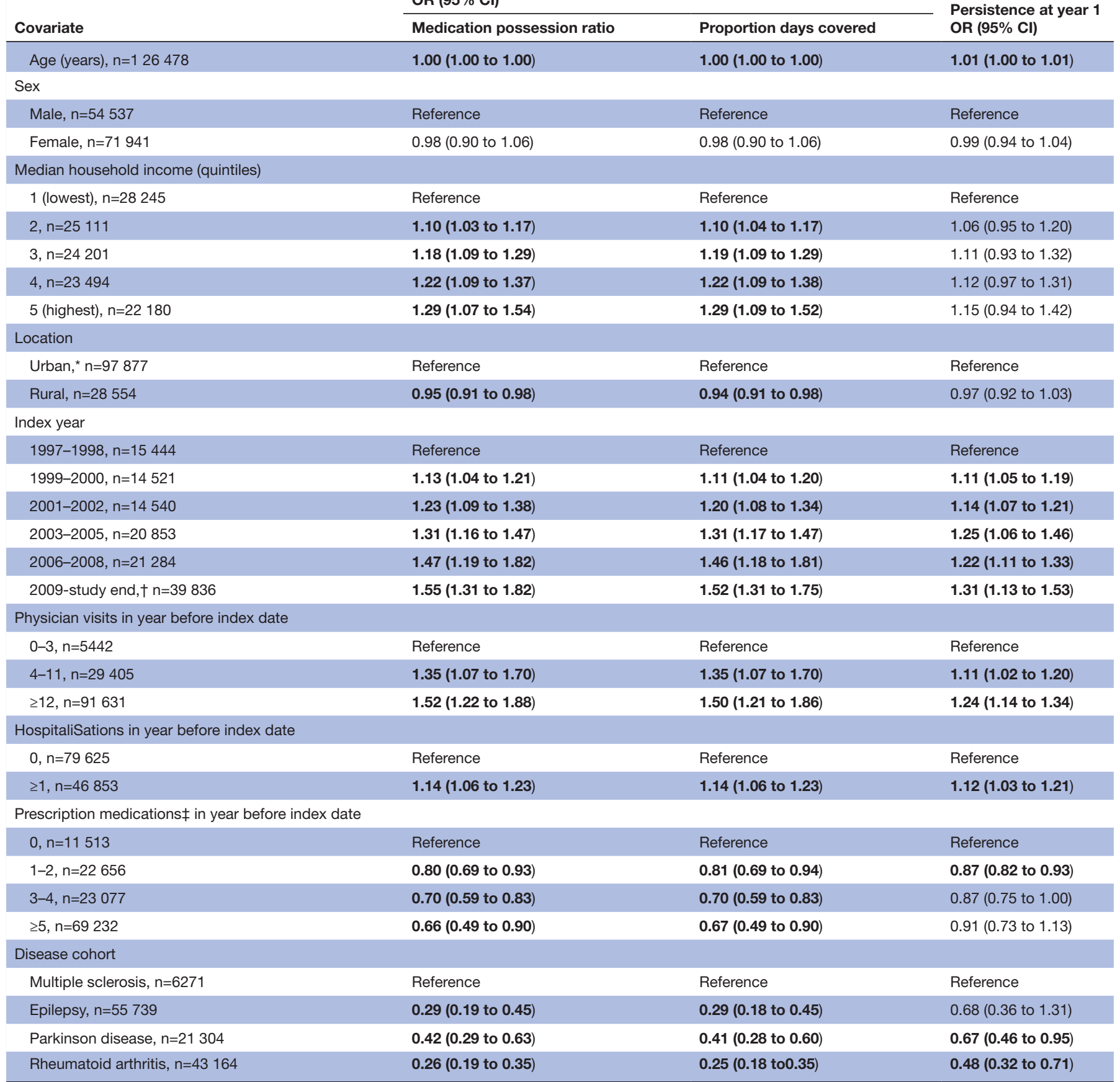

Bold values indicate statistical significance.

${ }^{*}$ Definitions for urban vary between provinces: British Columbia, determined by forward sortation area (non-zero digit as the second character of the postal code) (https://www.ic.gc. ca/eic/site/bsf-osb.nsf/eng/br03396 html); Saskatchewan, population >1000 (https://www150 statcan gc ca/n1/pub/11-630-x/11-630-x2015004-eng htm); Manitoba, population >50 000 (only two cities in Manitoba are classified as urban).

†Study end was 31 December 2014 for British Columbia, and 31 December 2015 for Saskatchewan and Manitoba.

$\ddagger$ Number of non-study medication classes based on Anatomical Therapeutic Chemical Classification (https://www.whocc.no/atc_ddd_index/).

were observed across all four non-MS medication classes, including having optimal adherence to DMD.

During the study period, DMDs were prescribed by MS-specialist neurologists through MS centres in BC and MB. In SK, most individuals with MS were managed by community-based neurologists, none of whom had a practice dedicated to MS, and the one provincial MS centre at the time was focused on rehabilitative care. Despite this, adherence did not differ across provinces, and was actually found to be highest in SK in both the current (data not shown), and previous study. ${ }^{13}$ Combined, our findings suggest there is something unique about the DMDs themselves that is resulting in higher adherence, and support our hypothesis that the higher adherence seen in MS may 


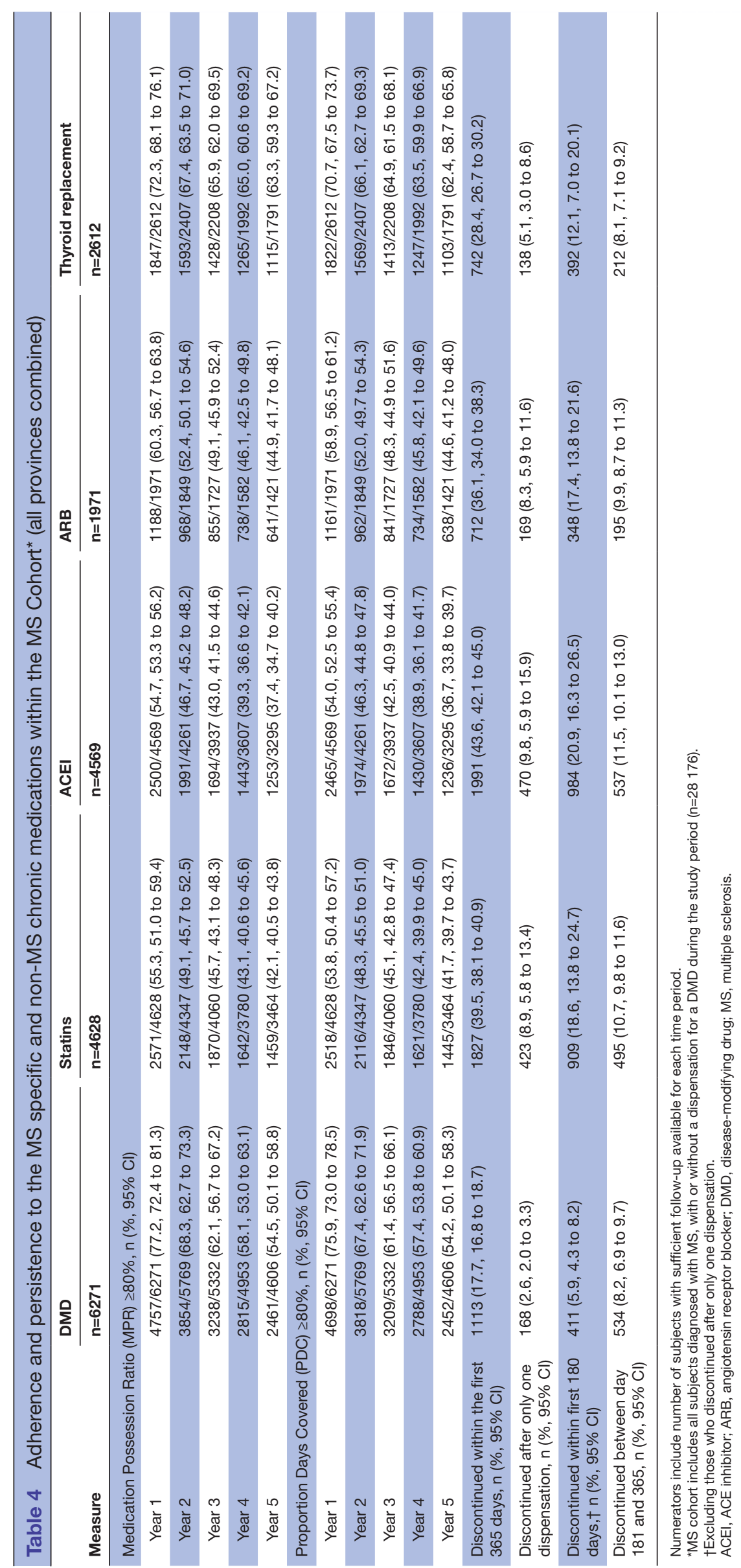


Table 5 Predictors of adherence to chronic-use medications within the MS cohort* at 1 year (all provinces combined) Medication possession ratio (MPR) at tear 1 OR $(95 \% \mathrm{Cl})$

\begin{tabular}{|c|c|c|c|c|}
\hline \multirow[b]{2}{*}{ Covariate } & \\
\hline & Statins $\mathrm{n}=\mathbf{8 7 9}$ & ACEI $n=766$ & ARB $n=363$ & Thyroid n=601 \\
\hline Age (years) & $1.03(1.01$ to 1.05$)$ & $1.02(1.00$ to 1.03$)$ & $0.99(0.94$ to 1.05$)$ & $1.02(1.00$ to 1.04$)$ \\
\hline \multicolumn{5}{|l|}{ Sex } \\
\hline Male & Reference & Reference & Reference & Reference \\
\hline Female & $0.79(0.50$ to 1.26$)$ & 0.51 (0.36 to 0.72$)$ & $0.53(0.29$ to 0.96$)$ & 1.33 (0.66 to 2.65$)$ \\
\hline \multicolumn{5}{|l|}{$\begin{array}{l}\text { Median household income } \\
\text { (quintiles) }\end{array}$} \\
\hline 1 (lowest) & Reference & Reference & Reference & Reference \\
\hline 2 & 1.70 (1.04 to 2.77$)$ & $0.95(0.29$ to 3.14$)$ & 1.04 (0.47 to 2.31$)$ & $1.13(0.60$ to 2.12$)$ \\
\hline 3 & 1.26 (0.50 to 2.86$)$ & 0.79 (0.39 to 1.59$)$ & 1.05 (0.27 to 4.08$)$ & 1.32 (0.68 to 2.53$)$ \\
\hline 4 & 0.99 (0.63 to 1.57$)$ & 0.76 (0.20 to 2.82$)$ & 1.04 (0.15 to 7.37$)$ & 1.02 (0.50 to 2.09$)$ \\
\hline 5 (highest) & 1.31 (0.82 to 2.11$)$ & $0.80(0.30$ to 2.15$)$ & 1.27 (0.31 to 5.12$)$ & 0.90 (0.47 to 1.69$)$ \\
\hline \multicolumn{5}{|l|}{ Location } \\
\hline Urban† & Reference & Reference & Reference & Reference \\
\hline Rural & $0.64(0.42$ to 0.97$)$ & 0.83 (0.58 to 1.21$)$ & 0.84 (0.47 to 1.53$)$ & 1.01 (0.62 to 1.65$)$ \\
\hline Index year & 1.02 (0.97 to 1.07$)$ & 1.02 (0.95 to 1.08$)$ & $1.00(0.90$ to 1.11$)$ & 1.01 (0.98 to 1.05$)$ \\
\hline $\begin{array}{l}\text { Mean no of physician visits in } \\
\text { year before index date }\end{array}$ & 1.01 (0.99 to 1.03$)$ & 0.99 (0.98 to 1.00$)$ & 1.01 (0.99 to 1.03$)$ & 1.00 (0.99 to 1.02$)$ \\
\hline $\begin{array}{l}\text { Mean no of hospitalisations in } \\
\text { year before index date }\end{array}$ & 0.99 (0.80 to 1.22$)$ & $1.15(0.90$ to 1.47$)$ & 0.88 (0.64 to 1.22$)$ & 1.40 (0.97 to 2.01$)$ \\
\hline $\begin{array}{l}\text { Mean no of prescription } \\
\text { medications } \ddagger \text { in year before index } \\
\text { date }\end{array}$ & $1.04(1.00$ to 1.08$)$ & $1.05(1.00$ to 1.09$)$ & 1.04 (0.98 to 1.11$)$ & 0.98 (0.93 to 1.03$)$ \\
\hline \multicolumn{5}{|l|}{$\begin{array}{l}\text { Adherence (MPR) to DMD at year } \\
1 \geq 80 \%\end{array}$} \\
\hline No & Reference & Reference & Reference & Reference \\
\hline Yes & 1.35 (0.94 to 1.95$)$ & $1.83(1.23$ to 2.71$)$ & 1.18 (0.66 to 2.13$)$ & 1.33 (0.85 to 2.07$)$ \\
\hline
\end{tabular}

Bold values indicate statistical significance.

*Only includes subject who received at least one dispensation for a DMD and a chronic-used medication during the study period.

†Definitions for urban vary between provinces: BC, determined by forward sortation area (non-zero digit as the second character of the postal code) (https://www.ic.gc.ca/eic/site/bsfosb.nsf/eng/br03396.html); SK, population >1000 (https://www150.statcan.gc.ca/n1/pub/11-630-x/11-630-x2015004-eng.htm); MB, population >50 000 (only two cities in Manitoba are classified as urban).

$\ddagger$ Number of non-study medication classes based on Anatomical Therapeutic Chemical Classification (https://www.whocc.no/atc_ddd_index/).

ACEI, ACE inhibitor; ARB, angiotensin receptor blocker; DMD, disease-modifying drug; MB, Saskatchewan; SK, Saskatchewan.

be due to the specialised DMD management and support programmes provided to individuals.

In Canada, each individual pharmaceutical company with a marketed DMD for MS has an established patient support programme. ${ }^{44}$ These programmes are often led by nurse educators, and provide individualised training, and ongoing support and follow-up at no-cost to individuals. Although the literature is full of examples of interventions aimed at improving adherence, few methods have proven effective or sustainable. ${ }^{4} 511$ These DMD support programmes differ from most existing adherence interventions in that they provide comprehensive and continuous support, and may serve as an example for future interventions.

Our study is not without limitations. As with all observational studies, we were not able to control for all potential confounders. With administrative data, we lacked information on disease severity, and potential adverse effects, which may affect adherence and persistence. Although we excluded subjects who were pregnant, we were not able to determine the reason(s) for discontinuations or non-adherence. We did not include a variable specifically measuring comorbidity, as there is no optimal method for estimating comorbidity burden in administrative data. ${ }^{45}$ However, we included prior healthcare utilisation and medication use, which have previously been used as proxy measures for comorbidity, and which predict important outcomes such as mortality. ${ }^{13546}$ Although there is always a potential for lack of efficacy with any drug, we are not concerned that it affected our results. All study outcomes were estimated using a class effect, so switching between drugs was allowed. Therefore, if one agent was not effective, a subjectl was not 'penalised' for switching to another drug. In all of the study diseases it is highly unlikely that a lack of efficacy of one agent would results in a complete withdrawal of all drugs, especially within the first year of therapy. We had to make an assumption of the days' supply for the adherence calculations using SK data. This assumption may have resulted in lower adherence levels; however, the assumption was applied consistently across all cohorts, and therefore, would not affect the adherence comparisons. Finally, we arbitrarily chose a threshold 
of $80 \%$ to define optimal adherence. This threshold is widely used in the adherence literature and has been associated with fewer hospitalisations and deaths, and allowed for comparability of our findings. ${ }^{2} 478$ Nevertheless, this large cohort study included over 126000 subjects from 3 Canadian provinces that provide universal healthcare coverage. Because all data were population based, and only incident users were included in our analyses, we minimised several biases often noted in adherence studies. ${ }^{490}$ The use of identical data sources, definitions, outcomes and time periods ensured our findings were robust and not due to variability between study methodologies.

To date, there has been little success in identifying effective interventions to improve medication adherence. ${ }^{451112}$ Reasons for non-adherence are complex and few predictors have been consistently associated with levels of adherence across diseases. ${ }^{2}{ }^{9}$ As such, diseasespecific adherence evaluations and comparisons such as ours are imperative. Given the impact of non-adherence on increased mortality, morbidity and healthcare costs, ${ }^{247}$ further examination of DMD adherence and the effects of access to, and quality of, these support programmes in other regions is warranted to better understand their potential as a model for improving adherence to medications for other chronic conditions.

Acknowledgements We thank the BC Ministry of Health, BC Vital Statistics Agency and BC PharmaNet for approval and support with accessing provincial data, and Population Data BC for facilitating approval and use of the data. All inferences, opinions and conclusions drawn in this paper are those of the authors, and do not reflect the opinions or policies of the Data Steward(s). The authors acknowledge the Manitoba Centre for Health Policy for use of the Population Health Research Data Repository under project \#2016-044 (HIPC \#2016/2017-24). The results, inferences, opinions and conclusions presented are those of the authors and no official endorsement by the Manitoba Centre for Health Policy, Manitoba Health, the Data Stewards or other data providers is intended or should be inferred. This study is based, in part, on deidentified data provided by the Saskatchewan Ministry of Health and eHealth Saskatchewan.

Contributors CE, RAM, HT and DB designed the study and CE obtained funding. CE drafted the manuscript. SY, FZ and RW had access to the data in the study and take responsibility for the integrity of the data and accuracy of the data analyses. $\mathrm{CE}, \mathrm{RAM}, \mathrm{HT}, \mathrm{DB}, \mathrm{EK}, \mathrm{SY}, \mathrm{FZ}$ and RW were involved with the interpretation of the data, critically revising the manuscript, and have approved the final version to be published.

Funding This work was supported by the Canadian Institutes of Health Research (Appl \# 363635). The study sponsor had no role in the study design, data collection, data analysis, interpretation of results, writing of the manuscript, or decision to submit.

Disclaimer The interpretation and conclusions contained herein do not necessarily represent those of the Government of Saskatchewan, the Saskatchewan Ministry of Health, or eHealth Saskatchewan.

Competing interests All authors have completed the ICMJE uniform disclosure form at www.icmje.org/coi_disclosure.pdf and declare: CE reports grants from Canadian Institutes of Health Research during the conduct of the study; RAM reports grants from Canadian Institutes of Health Research during the conduct of the study; HT reports grants from Canada Research Chair for Neuroepidemiology and Multiple Sclerosis, grants from National Multiple Sclerosis Society, grants from Canadian Institutes of Health Research, other from National MS Society (2016, 2018), other from ECTRIMS-ACTRIMS $(2016,2017,2018,2019,2020)$, other from American Academy of Neurology $(2016,2019)$, grants and other from the MS Society of Canada, outside the submitted work; DB is the Chair in Patient Adherence to Drug Therapy within the College of Pharmacy and Nutrition, University of Saskatchewan. This position was created through unrestricted financial support from AstraZeneca Canada, Merck Canada, Pfizer Canada and the Province of Saskatchewan's Ministry of Health. None of the sponsors were involved in developing this study or writing the manuscript; no other relationships or activities that could appear to have influenced the submitted work. SY, FZ, RW and EK have nothing to disclose.

Patient consent for publication Not required.

Ethics approval Ethics approval was granted by the appropriate Research Ethics Boards in each province: the University of Manitoba Health Research Ethics Board (HS20076), the University of Saskatchewan Biomedical Research Ethics Board (16-244), and the University of British Columbia Clinical Research Ethics Board (H-16-02411). Approval for administrative data access was provided by the relevant provincial data steward.

Provenance and peer review Not commissioned; externally peer reviewed.

Data availability statement № data are available. As per individual provincial data agreements, data sharing not available.

Supplemental material This content has been supplied by the author(s). It has not been vetted by BMJ Publishing Group Limited (BMJ) and may not have been peer-reviewed. Any opinions or recommendations discussed are solely those of the author(s) and are not endorsed by BMJ. BMJ disclaims all liability and responsibility arising from any reliance placed on the content. Where the content includes any translated material, BMJ does not warrant the accuracy and reliability of the translations (including but not limited to local regulations, clinical guidelines, terminology, drug names and drug dosages), and is not responsible for any error and/or omissions arising from translation and adaptation or otherwise.

Open access This is an open access article distributed in accordance with the Creative Commons Attribution Non Commercial (CC BY-NC 4.0) license, which permits others to distribute, remix, adapt, build upon this work non-commercially, and license their derivative works on different terms, provided the original work is properly cited, appropriate credit is given, any changes made indicated, and the use is non-commercial. See: http://creativecommons.org/licenses/by-nc/4.0/.

\section{ORCID iDs}

Charity Evans http://orcid.org/0000-0003-1409-0214

Shenzhen Yao http://orcid.org/0000-0002-7631-3404

Helen Tremlett http://orcid.org/0000-0001-5804-2535

\section{REFERENCES}

1 World Health Organization. Adherence to long-term therapies - evidence for action, 2003. Available: http://www.who.int/chp/ knowledge/publications/adherence_introduction.pdf [Accessed 1 Sep 2009].

2 Osterberg L, Blaschke T. Adherence to medication. N Engl J Med 2005;353:487-97.

3 Cutler RL, Fernandez-Llimos F, Frommer M, et al. Economic impact of medication non-adherence by disease groups: a systematic review. BMJ Open 2018;8:e0169982.

4 Costa E, Giardini A, Savin M, et al. Interventional tools to improve medication adherence: review of literature. Patient Prefer Adherence 2015;9:1303-14.

5 Kini V, Ho PM. Interventions to improve medication adherence: a review. JAMA 2018;320:2461-73.

6 Mongkhon P, Ashcroft DM, Scholfield CN, et al. Hospital admissions associated with medication non-adherence: a systematic review of prospective observational studies. BMJ Qual Saf 2018;27:902-14.

7 Cutler DM, Long G, Berndt ER, et al. The value of antihypertensive drugs: a perspective on medical innovation. Health Aff 2007;26:97-110.

8 Dutt M. Affordable Access to Medicines - A Prescription for Canada, 2014. Available: https://www.policyalternatives.ca/affordable-accessmedicines [Accessed 29 Jun 2020].

9 Haynes RB. Improving patient adherence: state of the art, with a special focus on medication taking for cardiovascular disorders. In: Burke L, Ockene I, eds. Compliance in healthcare and research. Armonk, New York: Futura Publishing Company, Inc, 2001: 3-24.

10 Raebel MA, Schmittdiel J, Karter AJ, et al. Standardizing terminology and definitions of medication adherence and persistence in research employing electronic databases. Med Care 2013;51:S11-21.

11 McDonald HP, Garg AX, Haynes RB. Interventions to enhance patient adherence to medication prescriptions: scientific review. JAMA 2002;288:2868-79.

12 Haynes RB, McDonald H, Garg AX, et al. Interventions for helping patients to follow prescriptions for medications. Cochrane Database Syst Rev 2002:CD000011. 
13 Evans C, Marrie RA, Zhu F, et al. Adherence and persistence to drug therapies for multiple sclerosis: a population-based study. Mult Scler Relat Disord 2016;8:78-85.

14 Melesse DY, Marrie RA, Blanchard JF, et al. Persistence to diseasemodifying therapies for multiple sclerosis in a Canadian cohort. Patient Prefer Adherence 2017;11:1093-101.

15 World Health Organization Collaborating Centre for Drug Statistics Methodology. ATC/DDD index 2020, 2020. Available: https://www. whocc.no/atc_ddd_index/ [Accessed 5 May 2020].

16 British Columbia Ministry of Health [creator] (2016). Medical Services (MSP) Payment Information File. V2. Population Data BC [publisher]. Data Extract. $\mathrm{MOH}, 2016$. Available: http://www.popdata.bc.ca/data

17 British Columbia Ministry of Health [creator]. PharmaNet (Data Extract). BC Ministry of Health [publisher]. Data Extract. Data Stewardship Committee, 2016. Available: http://www.popdata.bc/ data

18 British Columbia Vital Statistics Agency [creator]. Vital Statistics Deaths. Population Data BC [publisher]. Data Extract BC Vital Statistics Agency, 2016. Available: http://www.popdata.bc.ca/data

19 Canadian Institute for Health Information [creator]. Discharge Abstract Database (Hospital Separations). Population Data BC [publisher]. Data Extract. MOH, 2016. Available: http://www.popdata. bc.ca/data

20 British Columbia Ministry of Health [creator]. Consolidation File (MSP Registration \& Premium Billing). Population Data BC [publisher]. Data Extract. $\mathrm{MOH}, 2016$. Available: http://www.popdata.bc.ca/data

21 Marrie RA, Yu N, Blanchard J, et al. The rising prevalence and changing age distribution of multiple sclerosis in Manitoba. Neurology 2010;74:465-71.

22 Peschken CA, Hitchon CA, Garland A, et al. A population-based study of intensive care unit admissions in rheumatoid arthritis. $J$ Rheumatol 2016;43:43.

23 Reid AY, St Germaine-Smith C, Liu M, et al. Development and validation of a case definition for epilepsy for use with administrative health data. Epilepsy Res 2012;102:173-9.

24 Butt DA, Tu K, Young J, et al. A validation study of administrative data algorithms to identify patients with parkinsonism with prevalence and incidence trends. Neuroepidemiology 2014;43:28-37.

25 Canadian Institute of Health Information. The burden of neurological diseases, disorders and injuries in Canada. Ottawa, 2007.

26 Lagace C, O'Donnell S, McRae L. Life with arthritis in Canada. A personal and public health challenge, 2010. Available: http:// www.phac-aspc.gc.ca/cd-mc/arthritis-arthrite/lwaic-vaaac-10/pdf/ arthritis-2010-eng.pdf [Accessed 14 Feb 2016].

27 van den Bemt BJF, Zwikker HE, van den Ende CHM. Medication adherence in patients with rheumatoid arthritis: a critical appraisal of the existing literature. Expert Rev Clin Immunol 2012;8:337-51.

28 Malek N, Grosset DG. Medication adherence in patients with Parkinson's disease. CNS Drugs 2015;29:47-53.

29 Malek N, Heath CA, Greene J. A review of medication adherence in people with epilepsy. Acta Neurol Scand 2017;135:507-15.

30 Hamer HM, Dodel R, Strzelczyk A, et al. Prevalence, utilization, and costs of antiepileptic drugs for epilepsy in Germany--a nationwide population-based study in children and adults. J Neurol 2012;259:2376-84.

31 Alfian SD, Denig P, Coelho A, et al. Pharmacy-based predictors of non-adherence, non-persistence and reinitiation of antihypertensive drugs among patients on oral diabetes drugs in the Netherlands. PLoS One 2019;14:14.
32 Pharmacy Quality Alliance. PQA adherence measures, 2018. Available: https://www.pqaalliance.org/adherence-measures [Accessed 5 May 2020]

33 Leslie S. Using arrays to calculate medication utilization SAS global forum 2007 web site, 2007. Available: https://support.sas.com/ resources/papers/proceedings/proceedings/forum2007/043-2007. pdf [Accessed 7 Jul 2020].

34 Marrie RA, Cohen J, Stuve O, et al. A systematic review of the incidence and prevalence of comorbidity in multiple sclerosis: overview. Mult Scler 2015;21:263-81.

35 Marrie RA, Yu BN, Leung S, et al. Rising prevalence of vascular comorbidities in multiple sclerosis: validation of administrative definitions for diabetes, hypertension, and hyperlipidemia. Mult Scler 2012;18:1310-9.

36 Allison P. Logistic Regression Using SAS: Theory and Application. 2nd edn. Cary, NC: SAS Institute Inc, 2012.

37 Higgins JPT, Thompson SG, Deeks JJ, et al. Measuring inconsistency in meta-analyses. BMJ 2003;327:557-60.

38 Pasma A, Schenk CV, Timman R, et al. Non-adherence to diseasemodifying antirheumatic drugs is associated with higher disease activity in early arthritis patients in the first year of the disease. Arthritis Res Ther 2015;17:281.

39 Evans CD, Eurich DT, Remillard AJ, et al. First-Fill medication Discontinuations and nonadherence to antihypertensive therapy: an observational study. Am J Hypertens 2012;25:195-203.

40 Blackburn DF, Dobson RT, Blackburn JL, et al. Adherence to statins, beta-blockers and angiotensin-converting enzyme inhibitors following a first cardiovascular event: a retrospective cohort study. Can J Cardiol 2005;21:485-8.

41 Menzin J, Caon C, Nichols C, et al. Narrative review of the literature on adherence to disease-modifying therapies among patients with multiple sclerosis. J Manag Care Pharm 2013;19:S24-40.

42 Mathes T, Jaschinski T, Pieper D. Adherence influencing factors - a systematic review of systematic reviews. Arch Public Health 2014;72:37

43 Gast A, Mathes T. Medication adherence influencing factors-an (updated) overview of systematic reviews. Syst Rev 2019;8:112.

44 Multiple Sclerosis Society of Canada. Program and Services Pharmaceutical Company Support Programs, 2020. Available: https://mssociety.ca/support-services/programs-and-services/1051/ pharmaceutical-company-support-programs [Accessed 26 Jun 2020]

45 Quail JM, Lix LM, Osman BA, et al. Comparing comorbidity measures for predicting mortality and hospitalization in three population-based cohorts. BMC Health Serv Res 2011;11:146.

46 Schneeweiss S, Seeger JD, Maclure M, et al. Performance of comorbidity scores to control for confounding in epidemiologic studies using claims data. Am J Epidemiol 2001;154:854-64.

47 Simpson SH, Eurich DT, Majumdar SR, et al. A meta-analysis of the association between adherence to drug therapy and mortality. BMJ 2006;333:15.

48 Karve S, Cleves MA, Helm M, et al. Good and poor adherence: optimal cut-point for adherence measures using administrative claims data. Curr Med Res Opin 2009;25:2303-10.

49 Ray WA. Evaluating medication effects outside of clinical trials: newuser designs. Am J Epidemiol 2003;158:915-20.

$50 \mathrm{Li} \mathrm{X}$, Cole SR, Westreich D, et al. Primary non-adherence and the new-user design. Pharmacoepidemiol Drug Saf 2018;27:361-4. 